University of Nebraska - Lincoln

DigitalCommons@University of Nebraska - Lincoln

\title{
COLONY ISOLATION AND SECONDARY CULTURE OF FETAL PORCINE HEPATOCYTES ON STO FEEDER CELLS
}

\author{
Neil C. Talbot \\ United States Department of Agriculture- Agricultural Research Service \\ Vernon G. Pursel \\ United States Department of Agriculture- Agricultural Research Service \\ Caird E. Rexroad Jr. \\ United States Department of Agriculture- Agricultural Research Service \\ Thomas J. Caperna \\ United States Department of Agriculture- Agricultural Research Service \\ Anne M. Powell \\ United States Department of Agriculture-Agricultural Research Service, anne.powell@ars.usda.gov \\ See next page for additional authors
}

Follow this and additional works at: https://digitalcommons.unl.edu/usdaarsfacpub

Part of the Agricultural Science Commons

Talbot, Neil C.; Pursel, Vernon G.; Rexroad, Caird E. Jr.; Caperna, Thomas J.; Powell, Anne M.; and Stone, Roger T., "COLONY ISOLATION AND SECONDARY CULTURE OF FETAL PORCINE HEPATOCYTES ON STO FEEDER CELLS" (1994). Publications from USDA-ARS / UNL Faculty. 692.

https://digitalcommons.unl.edu/usdaarsfacpub/692

This Article is brought to you for free and open access by the U.S. Department of Agriculture: Agricultural Research Service, Lincoln, Nebraska at DigitalCommons@University of Nebraska - Lincoln. It has been accepted for inclusion in Publications from USDA-ARS / UNL Faculty by an authorized administrator of DigitalCommons@University of Nebraska - Lincoln. 


\section{Authors}

Neil C. Talbot, Vernon G. Pursel, Caird E. Rexroad Jr., Thomas J. Caperna, Anne M. Powell, and Roger T. Stone 


\title{
COLONY ISOLATION AND SECONDARY CULTURE OF FETAL PORCINE HEPATOCYTES ON STO FEEDER CELLS
}

\author{
NEIL C. TALBOT, VERNON G. PURSEL, CAIRD E. REXROAD, JR., THOMAS J. CAPERNA, ANNE M. POWELL, AND \\ ROGER T. STONE
}

\begin{abstract}
U.S. Department of Agriculture, Agricultural Research Service, Gene Evaluation and Mapping Laboratory, Beltsville Agricultural Research Center, Livestock and Poultry Sciences Institute, Beltsville, Maryland 20705 (N. C. T., V. G. P., C. E. R., A. M. P.); NonRuminant Animal Nutrition Laboratory (T. J. C.); and U.S. Meat Animal Research Center, Clay Center, Nebraska 68933 (R. T. S.)
\end{abstract}

(Received 24 January 1994; accepted 26 May 1994)

\begin{abstract}
SUMMARY
The secondary culture of non-transformed parenchymal hepatocytes has not been possible. STO feeder cell-dependent secondary cultures of fetal pig hepatocytes were established by colony isolation from primary cultures of 26-d fetal livers. The liver cells had the typical polygonal morphology of parenchymal hepatocytes. They also spontaneously differentiated to form small biliary canaliculi between individual cells or progressed further to large multicellular duct-like structures or cells undergoing gross lipid accumulation and secretion. The secondary hepatocyte cultures expressed alpha-fetoprotein (AFP), albumin, and $\beta$-fibrinogen mRNA, and conditioned medium from the cells contained elevated levels of transferrin and albumin. STO feeder cell co-culture may be useful for the sustainable culture of hepatocytes from other species.
\end{abstract}

Key words: differentiation; fetal; hepatocyte; pig.

\section{INTRODUCTION}

The secondary culture of normal parenchymal hepatocytes has not been possible (Williams et al., 1977; Guguen-Guillouzo et al., 1983; Perraud et al., 1991). In lieu of parenchymal hepatocyte cell strains, in vitro hepatocyte studies have been accomplished with the use of either primary hepatocyte cultures or transformed hepatocyte cell lines. However, these cell culture alternatives have several limitations that could be avoided if a method for the routine cloning and secondary culture of non-transformed parenchymal hepatocytes could be found.

Numerous human and rodent hepatocarcinoma derived cell lines have been established (Richardson et al., 1969; Aden et al., 1979). Transformation by immortalizing oncogenes has also yielded hepatocyte cell lines. For example, an interesting approach was the creation of hepatic cell lines from transgenic mice engineered to express c-myc or SV40 T antigen under the control of hepato-specific promoter/enhancer elements (Perraud et al., 1991). Although several of these hepatoma-derived and oncogene-transformed cell lines were minimally deviated and expressed various proteins representative of normal hepatocyte function, they are likely to be abnormal in several aspects, particularly, growth control. For example, some of these cell lines were highly tumorigenic when placed in vivo (Richardson et al., 1969; Knowles et al., 1980). In addition, while hepatocyte growth factor (HGF) and epidermal growth factor (EGF) were mitogenic for primary hepatocytes, HGF was reported to be cytostatic for the hepatoma cell lines HepG2, Hep3B, and H35 (Higashio and Shima, 1993), and EGF was inhibitory of the HA22T/VGH and Li7A hepatoma cell lines (Clementi et al., 1989). Finally, some human hepatoma cell lines also chronically produced hepatitis proteins (Aden et al., 1979). Thus, hepatomaderived cell cultures may confuse assessments of normal parenchymal hepatocyte biology in vitro, and in vivo assessments may not be possible.

Primary hepatocyte cultures were usually established after collagenase perfusion of rat or mouse livers (Berry and Friend, 1969; Williams et al., 1977). This technique was also amenable to the establishment of primary hepatocyte cultures in non-rodent species such as the pig (Caperna et al., 1985). However, establishing primary hepatocyte cultures is technically challenging, and their use can be problematic for several reasons. Their physical and biological characteristics can vary because of variations inherent in harvesting techniques and in the liver material itself. Also, other epithelial cells, fibroblasts, and macrophages can be common contaminants to the primary parenchymal hepatocyte cell culture. These other cell types may quickly overgrow or otherwise interfere with experimental manipulations and could confound measurements and results (Langenbach et al., 1979; Grisham, 1980; Caperna et al., 1985; Furukawa et al., 1987). Another problem has been the rapid loss of normal parenchymal hepatocyte morphology, metabolism, secretory activity, and enzymatic activity. Normal attributes such as albumin production and various enzymatic functions were usually lost within one to several weeks of establishment in primary culture (Langenbach et al., 1979; Guguen-Guillouzo et al., 1983; Sells et al., 1985). Given the problems that are inherent to primary hepatocyte culture, methods to sustainably culture these cells are of major interest.

Several methods for maintaining parenchymal hepatocytes in relatively longer term primary culture have been reported. For exam- 
ple, liver epithelioid cells were used as a co-culture system to extend the in vitro life span of rat hepatocytes to more than 2 mo. with maintenance of albumin secretion (Guguen-Guillouzo et al., 1983). Another report showed dimethyl sulfoxide extended the life span of functional primary rat hepatocyte cultures to several weeks (Isom et al., 1985). Also, extracellular matrix components were shown to be important for the long-term ( 1 to 2 mo.) in vitro maintenance of hepatocyte form and function (Bissell et al., 1987; Dunn et al., 1989). Most recently, long-term culture (2 mo.) of functional rat hepatocytes was achieved by creating spheroidal hepatocyte aggregates on poly-2-hydroxyethyl methacrylate-coated culture surfaces (Tong et al., 1992). None of these approaches, however, has enabled the routine secondary culture of non-transformed parenchymal hepatocytes. Thus, the ability to sustain normal parenchymal hepatocytes in secondary culture with the maintenance of hepatocyte-specific functions would be novel and of great value for the in vitro study of hepatocyte biology.

Previous work with the culture of the primitive ectoderm, or epiblast, of the 8-d pig blastocyst has led to the establishment of several epithelial cell lines (Talbot et al., 1993). Some of these were shown to have the morphological and biological characteristics of fetal pig parenchymal hepatocytes (manuscript submitted, Talbot et al., 1994). These cultures were established on and dependent on co-culture with a mitotically inactivated feeder layer of STO mouse embryonic fibroblasts. The derivation of fetal hepatocytes from the totipotent epiblast cells of the pig may have resulted from some inherent characteristics of the epiblast cells, or alternatively, could have reflected a culture environment selective for and conducive to pig hepatocyte culture. We now show that the STO co-culture environment is sufficient for the isolation and secondary culture of fetal pig parenchymal hepatocytes, which retained liver-specific functions over passage.

\section{Materials ANd Methods}

Cell culture. All cells were grown on tissue culture plastic ware (Nunc, Denmark and Falcon, Lincoln Park, NJ), and most cell culture reagents, including media, phosphate buffered saline (PBS), and trypsin-EDTA (0.025\% trypsin, $0.43 \%$ EDTA), were from GIBCO (Grand Island, NY). Fetal bovine serum (FBS) was from GIBCO or Hyclone (Logan, UT).

Primary pig fetal liver (PFL) cell cultures were started from 10-12 livers dissected from 26- or 27-d old fetal pigs. The fetal pigs originated from three sows over a 3-mo. period. The isolated livers were physically dispersed in complete medium by several aspirations through a $5-\mathrm{ml}$ pipette. Large fibrous material and clumps were allowed to settle for about $1 \mathrm{~min}$ at unit gravity. The top $90 \%$ of the liver cell suspension was removed and plated onto STO feeder cells in $60-\mathrm{mm}$ tissue culture dishes for primary culture.

Secondary culture was initiated by the isolation and passage of specific colonies (i.e., colony cloning). Parenchymal hepatocyte colonies consisting of about 100-200 cells were physically dissected from the monolayer. Individual colonies were transferred, using a Pasteur pipette with a drawn tip, to a 100- $\mu$ l drop of trypsin-EDTA and incubated at $37^{\circ} \mathrm{C}$ for $5 \mathrm{~min}$. About $95 \%$ of the trypsin-EDTA was removed, again with a drawn Pasteur pipette, and $100 \mu \mathrm{l}$ of complete medium was added to the cells. The trypsin-treated cells were separated into small clumps and single cells by repeated aspirations using a P-200 pipetman (Gilson, France) and transferred to a 4-well plate (Nunc) containing a STO-9 feeder cell monolayer. A second colony isolation or cloning was performed from the first secondary colony passage and from this population of about 100 cells mass cultures were grown. Approximate population doublings (PD) were assessed by microscopic observation of growth. Total PD was determined from the passage record, taking into account the specific split ratio at each passage. Total PD was confirmed by calculation of the expected total yield of cells starting from 50 cells that grew geometrically, assuming $100 \%$ plating efficiency. For example, a culture with a total of 18 PD starting from 50 cells would be expected to yield a total of approximately $13 \times 10^{6}$ cells.

Liver cell cultures were started and propagated in medium consisting of a 50:50 mix of Dulbecco's modified Eagle's medium (DMEM) with low glucose and Medium 199. The medium was supplemented with 5\% FBS, L-glutamine ( $4 \mathrm{mM}), \beta$-mercaptoethanol $(0.1 \mathrm{mM})$ (GIBCO), nucleosides (0.005 $\mathrm{mM}$ guanosine, $0.015 \mathrm{mM}$ adenosine, $0.005 \mathrm{mM}$ cytidine, 0.005 $\mathrm{m} M$ uridine, and $0.005 \mathrm{~m} M$ thymidine), nonessential amino acids $(0.5 \times)$, penicillin $(50 \mathrm{U} / \mathrm{ml})$, and streptomycin $(50 \mu \mathrm{g} / \mathrm{ml})(5 \%$ DMEM-199). Liver cell cultures were routinely passaged with trypsin-EDTA on STO feeder cells.

STO cells, a transformed mouse fibroblast line, were obtained from the American Type Culture Collection (ATCC), Rockville, MD. STO feeder cells were plated at $5 \times 10^{4}$ cells $/ \mathrm{cm}^{2}$ and prepared as described by Robertson, 1987, using mitomycin C inactivation. STO-9 is a subclone of the STO cell line created by transfection of the pSV2-Neo plasmid (Southern and Berg, 1982) and selection with the neomycin analog G-418 (1200 $\mu \mathrm{g} / \mathrm{ml}$ ) (GIBCO). STO and STO-9 were routinely passaged in DMEM (high glucose) with $10 \%$ FBS and antibiotics (10\% DMEM) using trypsin-EDTA.

ST pig testis cells (CRL 1746) were obtained from the ATCC. PICM-16, a dome-forming pig epiblast-derived cell line, and PICM-31, an undefined stem cell-like pig epiblast-derived cell culture, were previously described (Talbot et al., 1993).

Immunoblot analysis of conditioned medium. Unconcentrated, serumfree conditioned media samples or diluted pig serum (1:50) were prepared as previously described (Talbot et al., 1994). Samples were loaded onto a $10 \%$ polyacrylamide gel, and electrophoresis was performed under described conditions (Laemmli, 1970). Proteins were transferred to nitrocellulose $(0.2 \mu \mathrm{m})$, blocked with gelatin and probed with polyclonal antisera to whole pig serum, pig albumin, and pig transferrin. Specific immunoreactive antigens were visualized with alkaline phosphatase conjugated secondary antibody reagents (Sigma, St. Louis, MO).

Oil Red $O$ staining. Cell cultures were fixed with $4 \%$ formaldehyde for $10 \mathrm{~min}$ at $4^{\circ} \mathrm{C}$ and then rinsed with distilled water and $50 \%$ isopropyl alcohol at $4^{\circ} \mathrm{C}$. The fixed cells were stained for $5 \mathrm{~min}$ in $0.26 \% \mathrm{wt} / \mathrm{vol} \mathrm{Oil}$ Red $\mathrm{O}$ (Allied Chemical, Morristown, $\mathrm{NJ}$ ) in $60 \%$ isopropyl alcohol at $4^{\circ} \mathrm{C}$. Excess stain was removed by rinsing with distilled water or $50 \%$ isopropyl alcohol.

Northern blot analysis. Twenty micrograms of total RNA from STO mouse fibroblasts, 60-d fetal pig liver, 27-d fetal pig liver, adult pig liver, and PFL cell cultures were harvested, separated on $0.8 \%$ agarose gels, and transferred to Zetaprobe membrane (Bio-Rad, Hercules, CA) by methods previously described (Chomczynski and Sacchi, 1987; Fourney et al., 1988). The Northern blots were hybridized with random primed ${ }^{32} \mathrm{P}$-labeled cDNA probes to pig AFP (C137), pig albumin (C230), or pig $\beta$-fibrinogen (C6), all provided by Dr. Roger T. Stone (U.S. Meat Animal Research Center, Clay Center, NE), and followed by autoradiograph in each case. Hybridizations with a human glyceraldehyde-3-phosphate dehydrogenase DNA probe (pSP6-G3PDH, Ambion, Austin, TX) or a rabbit $\alpha$-actin DNA probe, provided by Dr. Roger T. Stone, were subsequently performed as loading controls. However, neither the G3PDH nor the $\alpha$-actin probing proved to be an effective or definitive measure of the RNA harvested from in vivo tissue.

Reagents and chemicals. Mitomycin C, uridine, adenine, cytidine, and thymidine, $\beta$-mercaptoethanol, were obtained from Sigma.

\section{Results}

The PFL primary cultures were a dense mixture of blood cells, macrophages, and small parenchymal hepatocyte colonies (Fig. 1 A). Fibroblasts and other epithelial cells must have also been present but could not be identified with confidence. The medium on the plates was changed every 2-3 d, and, in doing so, the blood cells were greatly reduced in number. By 6-7 d in primary culture, parenchymal hepatocytes, which had set down as small clumps or as single cells, began to multiply into discrete monolayer colonies growing on top of the STO cells (Fig. $1 \mathrm{~A}$ ). Also, large numbers of macrophages were present either in a semiattached round form or 

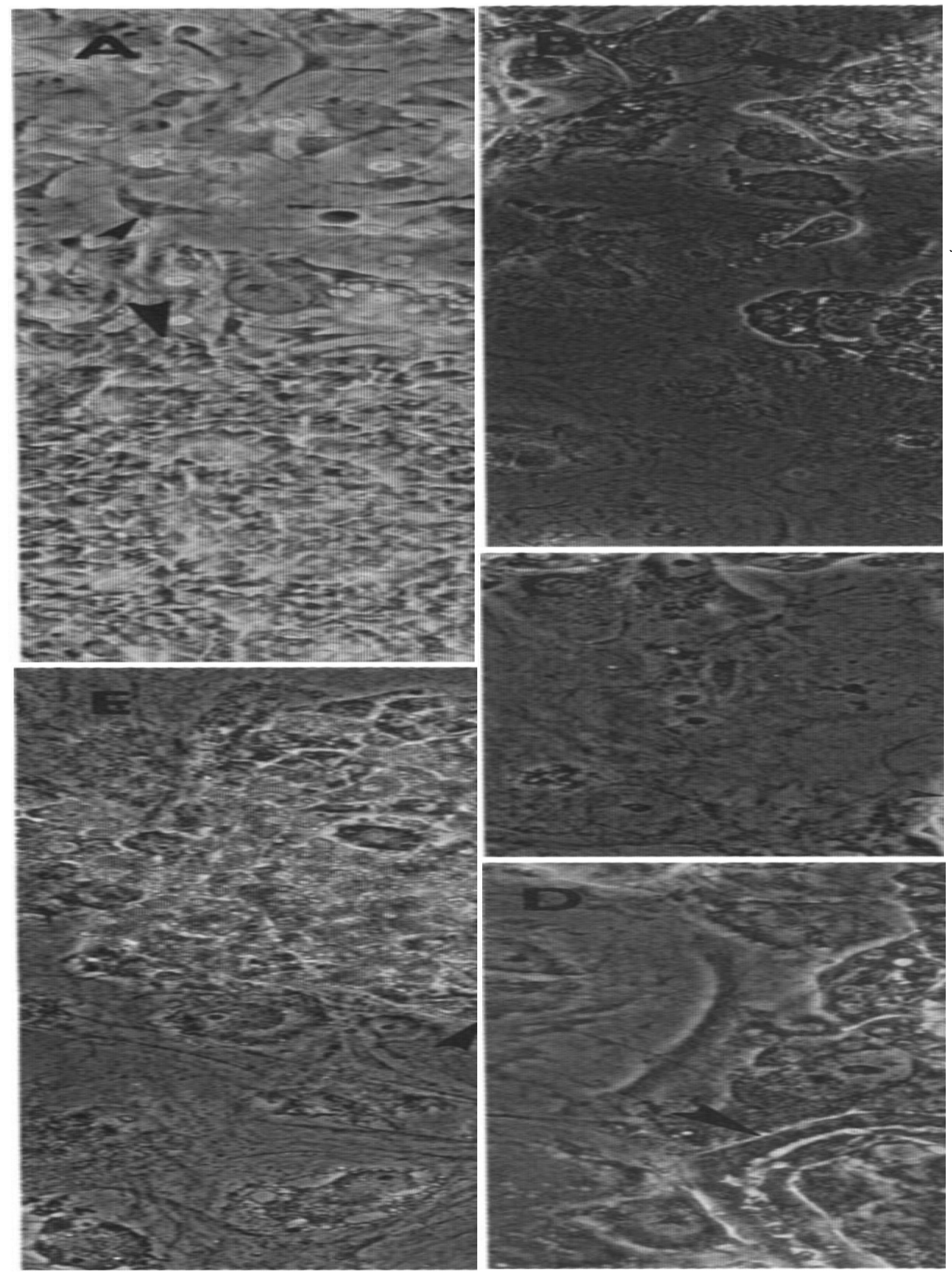

Fig. 1. Primary and secondary co-culture of fetal pig hepatocytes on STO feeder cells. A, Primary colony of 26-d fetal pig hepatocytes (large arrows) and macrophages (small arrows). Bar $=42 \mu \mathrm{m}$. B. Secondary culture of PFL-2 cells, Passage 13, with monolayer colonial out growth (large arrows), with multicellular ductal formation (intermediate arrows), and with accumulation of gross amounts of lipid (small arrows). Bar $=84 \mu \mathrm{m}$. C, PFL-2 cells, Passage 13, with formation of biliary canaliculi between individual monolayer cells (large arrows) and accumulation of lipid (small arrows). Bar $=42 \mu \mathrm{m} . D$, PFL-2 cells in multicellular ductal formation (arrows). Bar $=42 \mu \mathrm{m}$. E, PFL-2 cells, Passage 9, Oil Red 0 stained, showing gross amounts of intracellular (small arrow) and extracellular (large arrow) lipid accumulation. Bar $=42 \mu \mathrm{m}$. 
TABLE 1

CRYOPRESERVATION AND PASSAGE HISTORY OF PFL CULTURES

\begin{tabular}{rlc}
\hline PFL\# & $\begin{array}{c}\text { Post-Colony Cloning Cryopreservation } \\
\text { Passage Level }\left(\geq 10^{5} \text { cells frozen) }\right.\end{array}$ & $\begin{array}{c}\text { Post-Colony Cloning } \\
\text { Approximate Maximum PD }\end{array}$ \\
\hline 1 & P5 & 5 \\
2 & P9, P10, P12, P13, P14 & 18 \\
3 & P6, P7 & 12 \\
4 & P3 & 6 \\
5 & - & 2 \\
6 & - & 2 \\
7 & P3 & 8 \\
8 & - & 2 \\
9 & - & 1 \\
10 & - & 1 \\
\hline
\end{tabular}

as firmly attached ameboid cells with multiple pseudopods (Fig. 1 A). The primary pig parenchymal hepatocytes were of typical morphology (Caperna et al., 1985). The cells were polygonal with welldefined boundaries and had phase-contrast dark, granular cytoplasm with prominent nuclei and nucleoli. The cells were uniformly mononuclear.

Well-developed and discrete primary parenchymal hepatocyte colonies were morphologically identified and colony cloned after about 1 wk in culture. Polygonal monolayer structure was uniform and other contaminating cell types (macrophages, fibroblasts, and other epithelial cells) had not overgrown the culture at this time. Also, the parenchymal hepatocytes had not grown to confluence. Several colony clonings were performed from about a dozen primary fetal pig hepatocyte cultures.

In 7-10 days, secondary colonies were cloned from the first colony cloned cultures. Colonies composed of about 50-100 parenchymal hepatocytes and free of contaminating cells (predominantly macrophages) were colony cloned. Parenchymal hepatocytes cultures grown up from the second colony clonings were free of other cell types. The cultures were routinely passaged onto fresh STO-9 feeder cells using trypsin-EDTA. Once the secondary cultures were scaled up to $10^{5}$ to $10^{6}$ cells, freeze downs were made, and the cultures were numerically designated according to their order of derivation as PFL cultures (Table 1).

In static maintenance culture of 1-2 weeks on ST0-9 feeder cells, the fetal pig hepatocytes spontaneously differentiated. All the PFL cell cultures formed monolayer colony groupings that either developed biliary canaliculi between their individual cells or formed multicellular duct-like structures (Fig. $1 B, C, D$ ). In addition, monolayers of the PFL-2 culture developed gross intracellular and extracellular accumulations of droplets after 5-6 wk in static maintenance culture. The droplets stained intensely with the lipid-specific stain Oil Red $O$ (Fig. $1 E$ ). The ductal and lipid accumulation differentiation events appeared to be mutually exclusive as they were never observed to occur together in the same colony of cells. However, biliary canaliculi formation was present in, and appeared to precede, both the ductal and lipid differentiation. Terminal differentiation was prevented by passaging the cells at regular intervals of 5-7 d.

Phase-contrast microscopy of the fully formed duct-like structures showed a polar cell anatomy. The cells assumed a columnar arrangement with a smooth outer surface and an irregular inner lumenal surface. Phase-contrast-dense material accumulated at the cytoplasmic membranes of the inner lumenal surface indicative of possible secretory function. Ductal structures were first observed in the PFL cultures after the first colony cloning. The late passage ( $\geq 18$ PD; 14 passages) PFL-2 cultures retained this differentiation potential (other PFL cultures could not be passaged to this extent, see Table 1). Duct formation and lipid accumulation appeared to be terminal differentiation events because the cells, while viable, were nondividing when passaged.

AFP, albumin, and $\beta$-fibrinogen gene expression is characteristic of parenchymal hepatocytes and occurs at different times during development. In the pig, AFP was strictly expressed in fetal or neonatal pig liver, while albumin and $\beta$-fibrinogen expression was found in both the adult and fetal liver (Stone, 1989). PFL-2 RNA was assayed by Northern blot analysis at Passage 13 from 50-75\% confluent monolayers and was positive for AFP, albumin (Fig. 2 lanes 2 and 3), and $\beta$-fibrinogen (Fig. 3 lane 4) gene expression. The expression levels of the AFP and albumin genes were similar in recently passaged PFL-2 cells compared to 3 -wk-old PFL-2 cells (Fig. 2 lanes 2 and 3). Coincident analysis of mRNA harvested from 26- to 27-d fetal pig livers, 60-d fetal pig liver, and adult pig liver showed that, as expected, AFP expression was present only in the fetal liver while albumin and $\beta$-fibrinogen were expressed in both fetal and adult liver (Figs. 2 and 3) (Stone, 1989). STO feeder cells were negative for the expression of AFP, albumin and $\beta$-fibrinogen (Fig. 2 lane 4; Fig. 3 lane 3).

PFL-2 conditioned medium was assayed for the presence of transferrin, AFP, and albumin. Serum-free culture medium was conditioned for $3 \mathrm{~d}$ by a 50-75\% confluent monolayer of PFL-2, which had been in static culture for $2 \mathrm{wk}$. Conditioned medium from STO feeder cells alone was compared as a control for STO secretory activity and for the presence of residual proteins from the initial 10\% FBS culture condition. The unconcentrated conditioned media were analyzed by SDS-PAGE and immunoblotting with speciesspecific polyclonal antibodies to transferrin, AFP, albumin, and to whole pig serum. PFL-2 conditioned medium contained large amounts of albumin, transferrin (Fig. 4), and AFP (data not shown). STO feeder cell conditioned medium did not contain immunoreactive secretory products, demonstrating that the PFL-2 cells secreted the transferrin, albumin, and AFP.

\section{Discussion}

We have described a simple method for the establishment of fetal pig parenchymal hepatocytes in primary culture and their routine secondary culture. Previous studies described culture conditions that allowed for the maintenance of adult and fetal parenchymal hepatocytes (rat and human) in primary culture or very limited secondary culture (Berry and Friend, 1969; Williams et al., 1977; Sirica et al., 1979; Sawada et al., 1987; Sand and Christoffersen, 1988; Sells et al., 1985). Similar methods were also successful in the primary culture of pig hepatocytes (Caperna et al., 1985). These studies, and many others, demonstrated refinements in cell harvesting techniques, defined medium, and extracellular matrix requirements. Liver-specific functions were usually maintained for a week or two and occasionally for as long as several weeks (Isom et al., 1985; Tong et al., 1992; Sells et al., 1985; Dunn et al., 1989). In contrast, the PFL-2 cells maintained parenchymal morphology, the expression of liver-specific mRNA and proteins, and their potential to differentiate functionally into large multicellular ductal 
structures or lipid accumulating colonies after successive colony clonings and multiple passages in culture. The PFL-2 cells were in culture for over 3 mo. during their passage history.

The nature of the duct-like structures formed by the PFL-2 cells

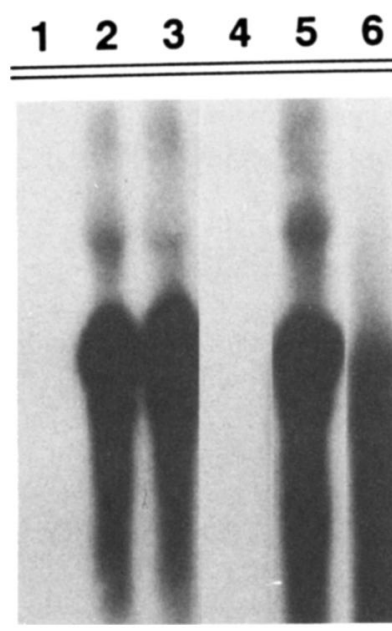

A
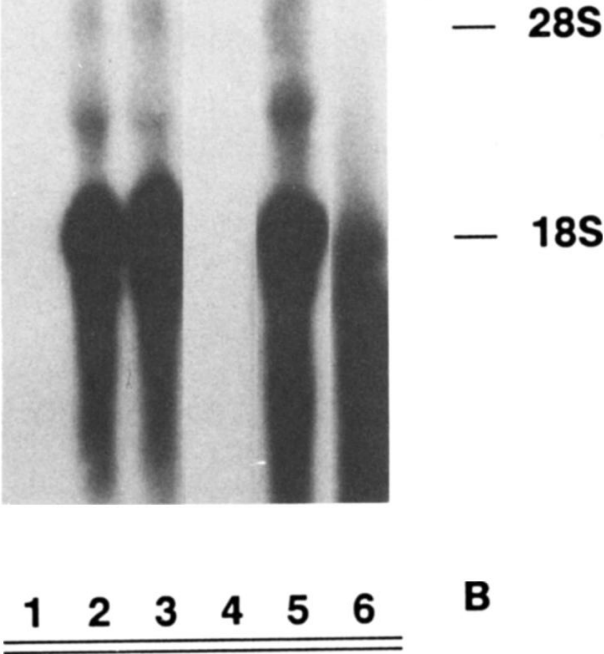

B

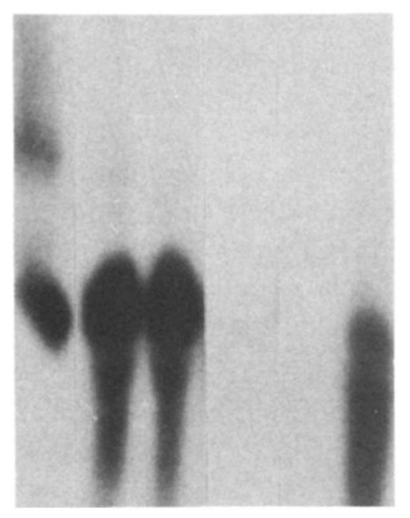

$-28 S$

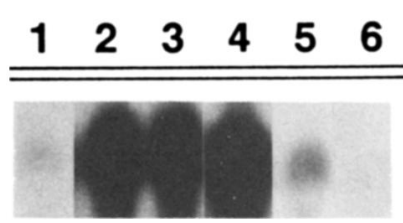

Fig. 2. Northern blot analysis of PFL-2 $\alpha$-fetoprotein (AFP) and albumin mRNA expression. Northern blots were hybridized with ${ }^{32} \mathrm{P}$-labeled cDNA probes to $(A)$ pig AFP (C137), (B) pig albumin (C230), followed by autoradiography. Hybridization with a human glyceraldehyde-3-phosphate dehydrogenase DNA probe (pSP6-G3PDH) was performed as an mRNA loading control $(C)$. AFP and albumin probes detected single bands approximately $2 \mathrm{~kb}$ in length and a single $1.4 \mathrm{~kb}$ was detected by the G3PDH probe. Arrows indicate the positions of $28 \mathrm{~S}$ and 18S RNA. In vivo adult liver, lane 1; PFL-2, Passage 13, 8-d culture period, lane 2; PFL-2, Passage 13, 20-d culture period, lane 3; STO embryonic mouse fibroblasts, lane 4; in vivo 27 -d fetal pig liver, lane 5; and in vivo 60-d pig fetal liver, lane 6.
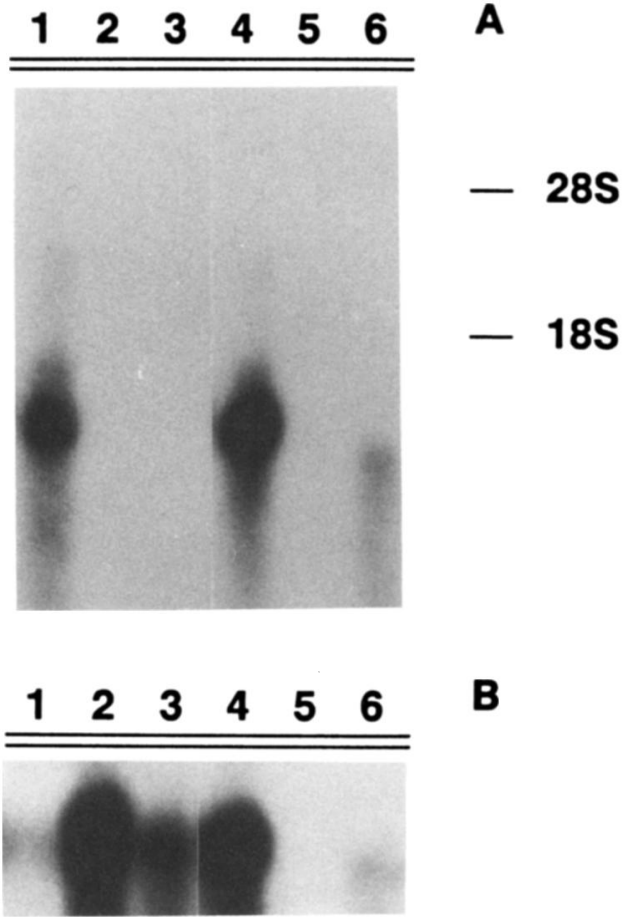

B

Fig. 3. Northern blot analysis of PFL-2 $\beta$-fibrinogen mRNA expression. The Northern blot was hybridized with a ${ }^{32} \mathrm{P}$-labeled cDNA probe to pig $\beta$-fibrinogen, followed by autoradiography. Hybridization with an $\alpha$-actin DNA probe was performed as an mRNA loading control. The $\beta$-fibrinogen probe detected a single band of approximately $1.6 \mathrm{~kb}$ in length and the $\alpha$-actin probe detected a single band of $1.8 \mathrm{~kb}$. Arrows indicate the positions of $28 \mathrm{~S}$ and 18S RNA. In vivo adult pig liver, lane 1; ST pig testis cell line, lane 2; Mitomycin C treated STO mouse embryonic fibroblasts, lane 3; PFL-2, Passage 13, lane 4; blank, lane 5; and in vivo 26-d fetal pig liver, lane 6.

(and PICM-19 cells, manuscript submitted, Talbot et al., 1994) was not defined. Given their derivation from the parenchymal hepatocytes and their striking morphology, it is possible that they represent the in vitro equivalent of the in vivo liver bile ductules. The PFL-2 cultures that were assayed for liver-specific mRNA and protein expression were nearly devoid of ductal formations. Therefore, our existing data cannot support any conjecture as to gene and protein expression of the ductal cells specifically. However, the PICM-19 cells (manuscript submitted, Talbot et al., 1994) that formed ductal structures extensively showed similar expression levels of AFP, albumin, transferrin, and $\beta$-fibrinogen. Thus, the alternative phenotypes, polygonal hepatocyte with biliary canaliculi versus pseudo-columnar multicellular ductal formation, may not vary in the expression of at least these liver-specific proteins. Analysis for bile duct epithelium markers, such as gamma-glutamyltransferase (GGT) activity, would give more specific indications as to the nature of the PFL-2 ductal cells. We anticipate that the PFL-2 ductular structures will be positive for GGT because preliminary histochemical staining for GGT in the PICM-19 cells showed dramatic induction of GGT activity at the apical surfaces of the cells as they associated and formed ductal structures (unpublished observation).

The PFL-2 cells that formed ductal structures at early or late passage represented only a small percentage of the total number of 


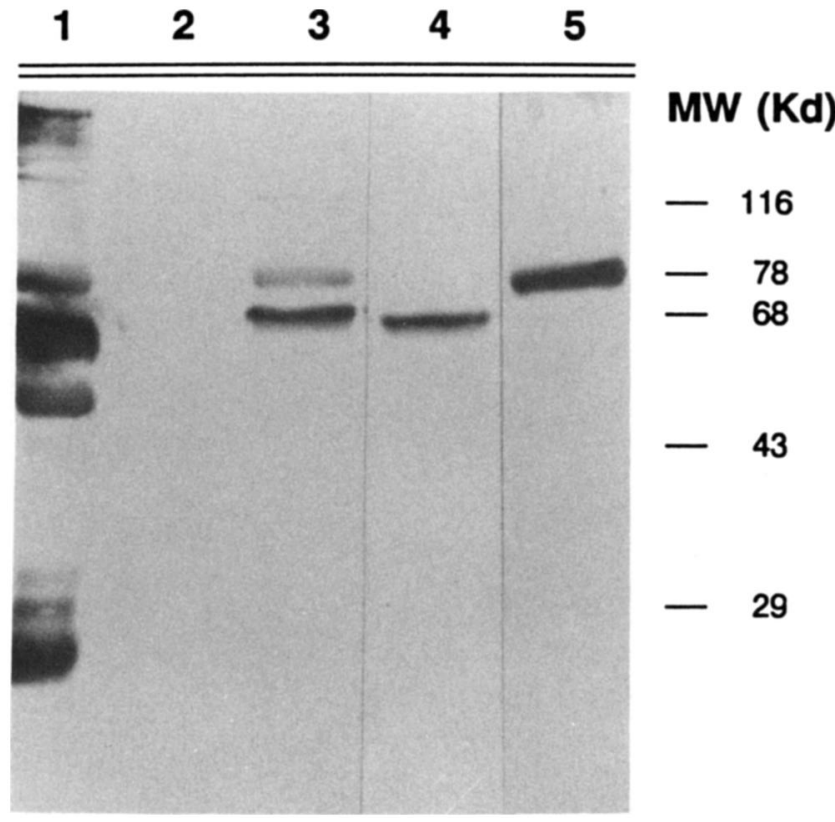

Fig. 4. Immunoblot analysis of PFL-2 transferrin and albumin secretion. Antibody reactions of the Western blot were as follows: anti-whole pig serum (lanes 1, 2 and 3), anti-pig albumin (lane 4), and anti-pig transferrin (lane 5). Adult pig serum, lane 1; STO embryonic mouse fibroblast conditioned medium, lane 2; PFL-2, Passage 9, conditioned medium, lanes 3, 4 and 5 .

cells. This could be viewed as a recapitulation of the in vivo situation where the ductular cells represent a small percentage of the total liver mass. Also, the number of cells per unit length of ductal structure was greatly reduced in the PFL-2 cultures when compared with the PICM-19 cell line's ductal structures (Fig. $1 D$ ). This low relative cell density within the ductal structure and the low incidence of ductal formation in general may reflect preexisting differentiation commitment and a lack of stem cell character in the PFL-2 culture. That is, it is possible that the PFL low-density ductal structures resulted because there were a finite number of cells committed to ductal formation in the population. In contrast, PICM-19 appeared to replenish its stem cell compartment over passage, and, therefore, retained its ability to differentiate into ductal structures with relatively high cell density (manuscript submitted, Talbot et al., 1994).

Although the porcine liver is not normally associated with in vivo lipid production, the enzymatic machinery for de novo fatty acid synthesis and processing is present in porcine liver (Mersmann, 1986). The production of triglycerides by the PFL-2 culture may result from the embryonic nature of the cells or from in vitro conditions (i.e., presence/lack of specific hormonal stimuli [e.g., insulin levels]), or possibly basic medium constituents. The addition of leukemia inhibitory factor (LIF) to the culture medium suppressed the ability of the epiblast-derived hepatocytes to accumulate and secrete lipid (manuscript submitted, Talbot et al., 1994; unpublished observation). Because LIF was demonstrated to inhibit lipoprotein lipase activity in adipocytes (Mori et al., 1989), it is possible that lipoprotein lipase is being similarly affected in the fetal pig hepatocyte cultures. This would also suggest that the lipid accumulation by the fetal pig hepatocytes is a sequestration and processing of lipid components in the culture medium (Guyton, 1986).
The primary and secondary culture of the fetal pig hepatocytes depended on the STO feeder cells. The use of feeder cells for the culture and cloning of fastidious cell types is a well-known method (Rheinwald and Green, 1975; Robertson, 1987) and was previously applied to liver cell culture (Langenbach et al., 1979; Michalopoulos et al., 1979; Guguen-Guillouzo et al., 1983). GuguenGuillouzo et al. (1983) showed that when adult rat hepatocytes were co-cultured with another liver epithelial cell type, the hepatocytes survived for more than 2 mo. while maintaining albumin secretion. Significantly, albumin secretion was induced by the addition of the epithelial feeder cells to the hepatocytes (Guguen-Guillouzo et al., 1983). While enhanced longevity in primary culture was not observed, Langenbach et al. (1979) and Michalopoulos et al. (1979) showed that the functional performance of adult rat hepatocytes was improved on $\mathrm{C} 3 \mathrm{H} / 10 \mathrm{~T}^{\mathrm{l}} / 2$ mouse fibroblasts and diploid human fibroblasts, respectively. Also, the widely used human liver carcinoma-derived cell lines HepG 2 and Hep3B were originally established on STO feeder layers (Aden et al., 1979). The explant technique used to establish the HepG2 and Hep3B cell lines is similar to the physical disruption technique used in establishing the PFL cultures. The cultures differ, however, in that the PFL hepatocytes were strictly feeder-dependent and had a finite in vitro life span while the carcinoma-derived human hepatocytes were adaptable to feeder-independent culture and are apparently infinite in growth potential. These differences probably reflect the non-transformed nature of the PFL cultures compared with the abnormal transformed character of the HepG2 and Hep3B cell lines. Although the HepG2 and HepB3 cell lines were initially cultured on STO feeder cells, complex morphological differentiation by the cells was not reported as in the PFL cultures. This may have resulted from differences between the STO co-cultures such as STO passage history and medium constituents. It seems possible, however, that the lack of demonstrated differentiation in the HepG2 and HepB3 cultures resulted from deregulated growth control and an inability of these cells to enter $G_{0}$ to form a viable fully differentiated state. The inability of the PFL cultures to sustain morphology and growth when plated off of the STO feeder cells indicates that, unlike HepG2 and Hep3B, the PFL cells are unable, in themselves, to complement the growth factor or cell-to-cell interactions provided by the STO cells.

Tissue interactions between hepatocyte progenitors and mesenchymal cells were shown to be necessary for the differentiation to functional hepatocytes (Wilson et al., 1963; Houssaint, 1980). It is presumed that the STO mouse fibroblasts are mesenchymal in origin (Gabbiani and Rungger-Brändel, 1981) and retain some of the inductive properties characteristic of the in vivo mesenchyme (Montesano et al., 1991a; Montesano et al., 1991b; Drew, 1923). The mechanisms that enable the STO feeder layer to support the serial cultivation and differentiation of the PFL cells are probably complex, although in some cell culture contexts, the STO function appears to be fairly simple. For example, mouse embryonic stem (ES) cell lines were established on STO feeder cells (Martin, 1981). Support for ES cells depended solely on the production of STO-derived LIF because similar ES cell lines were established with recombinant LIF without STO cells (Pease et al., 1990). Rheinwald and Green (1977) showed that the growth of a keratinizing epithelium was greatly improved on 3T3 feeder layers at a particular density. Also, in analogy with the functional differentiation of the PFL cells in STO co-culture, the differentiation of the cells into stratified 
squamous epithelium was strictly dependent on the 3T3 co-culture (Rheinwald and Green, 1975).

STO cells were shown to produce a variety of growth factors (Smith and Hooper, 1983; Montesano et al., 1991a; Montesano et al., 1991b; Schmitt et al., 1991; Matsui et al., 1992). Some of these were mediators of hepatocyte growth and function such as leukemia inhibitory factor (LIF) and hepatocyte growth factor (HGF). Hepatocytes were shown to express receptors for both LIF and HGF (Hilton et al., 1991; Prat et al., 1991). LIF was reported to induce acute phase response proteins in hepatocytes (Baumann and Wong, 1989), and HGF was widely described as a potent hepatocyte mitogen (Nakamura et al., 1984; Zarnegar and Michalopoulos, 1989; Strain et al., 1991). Both HGF and LIF stimulated replication of PICM-19 cells, putative liver stem cells isolated from the 8-d pig epiblast (manuscript in preparation). Thus, two growth factors directly related to hepatocyte growth and function are present in the STO feeder layer and may support the growth and differentiation of the fetal hepatocytes in primary and secondary culture. Other cell-to-cell interactions or growth factors seem necessary, however, since recombinant LIF, HGF, or STO conditioned medium alone did not support growth of the PFL cells (data not shown).

The PFL cultures established to date have not been sustainable past about $18 \mathrm{PD}$ after the initial two colony clonings (Table 1). This may reflect the normal in vitro senescent endpoint of pig liver cells (Rohme, 1981). The wide variation in senescent endpoints among the PFL cultures (Table 1) probably results from the random selection of colonies with differing growth potentials. If indefinitely self-renewing liver stem cells exist in the 25- to 27-d fetal pig liver, their isolation by colony cloning could easily be missed, especially if they represent only a small percentage of the cells present in the developing liver (Grisham, 1980; Sigal et al., 1992). In order to isolate stem cells or grow very large amounts of fetal pig hepatocytes, it might be useful to put the primary liver cell suspension through purification processes such as low speed gradient centrifugation (Caperna et al., 1985) to obviate the need for colony cloning. Larger replicating liver cell cultures might also be established from later embryonic stage livers or even from neonatal liver tissue. The initial isolation of larger numbers of fetal hepatocytes would probably support their continued passage for experimental purposes.

The isolation of fetal hepatocytes of other species on STO cells may be possible. A primary culture of bovine 30-d embryonic liver produced similar lipid and ductal forming hepatocytes that were also colony-cloned to homogeneity (manuscript in preparation). Experiments with fetal sheep, mouse, and rat hepatocyte co-culture on STO feeder cells have not been successful using the same techniques. With the mouse, rat, and sheep liver cultures, macrophage overgrowth was pronounced. The presence of relatively large numbers of macrophages could be detrimental because the pig hepatocytes were destroyed by exposure to tumor necrosis factor $(1 \mathrm{ng} /$ $\mathrm{ml}$ ), a cytokine that is secreted by the co-cultured macrophages (unpublished observations). The in vitro lifespan of the rodent hepatocytes may have also been a limiting factor. However, the fetal rat hepatocytes did not appear to be well maintained on the STO feeder cells. Although this may have resulted from the prolific macrophage overgrowth that occurred in the rat ·cultures, it may also simply reflect species differences in the response to the STO co-culture. It would be of interest to determine the STO co-culture growth re- sponses of other biomedically important fetal hepatocytes, such as those from monkey and human embryonic livers.

\section{ACKNOWLEDGMENTS}

The authors thank Ms. Leah Schulman for assistance in providing the fetal pigs. We thank Dr. Laura Lebow and Dr. Robert J. Hay for their reviews and suggestions on the manuscript, and Ms. Linda Neuenhahn for preparing the final typescript.

\section{REFERENCES}

Aden, D. P.; Fogel, A.; Plotkin, S., et al. Controlled synthesis of HBsAg in a differentiated human liver carcinoma-derived cell line. Nature 282:615-616; 1979.

Baumann, H.; Wong, G. G. Hepatocyte-stimulating factor III shares structural and functional identity with leukemia-inhibitory factor. J. Immunol. 143:1163-1167; 1989.

$\rightarrow$ Berry, M. N.; Friend, D. S. High yield preparation of isolated rat liver parenchymal cells. A biochemical and fine structural study. J. Cell Biol. 43:506-520; 1969.

Bissell, D. M.; Arenson, D. M.; Maher, J. J., et al. Support of cultured hepatocytes by a laminin-rich gel. Evidence for a functionally significant subendothelial matrix in normal rat liver. J. Clin. Invest. 79:801-812; 1987.

Caperna, T. J.; Failla, M. L.; Kornegay, E. T., et al. Isolation and culture of parenchymal and nonparenchymal cells from neonatal swine liver. J. Anim. Sci. 61:1576-1586; 1985.

$\rightarrow$ Chomczynski, P.; Sacchi, N. Single step method of RNA isolation by acid guandinium thiocyanate-phenol-chloroform extraction. Anal. Biochem. 162:156-159; 1987.

Clementi, M.; Festa, A.; Testa, I., et al. Expression of high-and low-affinity epidermal growth factor receptors in human hepatoma cell lines. FEBS 249:297-301; 1989.

Drew, A. H. Growth and differentiation in tissue culture. Br. J. Exp. Path. $4: 46-52 ; 1923$.

Dunn, J. C. Y.; Yarmush, M. L.; Koebe, H. G., et al. Hepatocyte function and extracellular matrix geometry: long-term culture in a sandwich configuration. FASEB J. 3:174-177; 1989.

Fourney, R. M.; Miyakoshi, J.; Day, R. S., et al. Northern blotting: efficient RNA staining and transfer. FOCUS 10:5-7; 1988.

Furukawa, K.; Shimada, T.; England, P., et al. Enrichment and characterization of clonogenic epithelial cells from adult rat liver and initiation of epithelial cell strains. In Vitro Cell. Dev. Biol. 23:339-348; 1987.

Gabbiani, G.; Rungger-Brändel, E. The fibroblast. In: Glynn, L. E., ed. Tissue repair and regeneration. Handbook of inflammation. Vol. 3. Amsterdam: Elsevier; 1981:1-50.

Grisham, J. W. Cell types in long-term propagable cultures of rat liver. Ann. NY Acad. Sci. 349:128-137; 1980.

Guguen-Guillouzo, C.; Clement, B.; Baffet, G., et al. Maintenance and reversibility of active albumin secretion by adult rat hepatocytes co-cultured with another liver epithelial cell type. Exp. Cell Res. 143:47-54; 1983.

Guyton, A. C. Textbook of medical physiology, 7th ed. Philadelphia: W. B. Saunders Co.; 1986:818-834.

Higashio, K.; Shima, N. Tumor cytoxicity activity of HGF-SF. Executive Skills 65:351-368; 1993.

Hilton, D. J.; Nicola, N. A.; Metcalf, D. Distribution and comparison of receptors for leukemia inhibitory factor on murine hemopoietic and hepatic cells. J. Cell Physiol. 146:207-215; 1991.

Houssaint, E. Differentiation of the mouse hepatic primordium. I. An analysis of tissue interactions in hepatocyte differentiation. Cell Differentiation 9:269-279; 1980.

$\rightarrow$ Isom, H. C.; Secott, T.; Georgoff, I., et al. Maintenance of differentiated rat hepatocytes in primary culture. Proc. Natl. Acad. Sci. 82:32523256; 1985.

Knowles, B. B.; Howe, C. C.; Aden, D. P. Human hepatocellular carcinoma cell lines secrete the major plasma proteins and hepatitis B surface antigens. Science 209:497-499; 1980. 
$\rightarrow$ Laemmli, U. K. Cleavage of structural proteins during the assembly of the head of bacteriophage T4. Nature 227:680-685; 1970.

Langenbach, R.; Malick, L.; Tompa, A., et al. Maintenance of adult rat hepatocytes on $\mathrm{C} 3 \mathrm{H} / 1 \mathrm{~T}^{1} / 2$ cells. Cancer Res. 39:3509-3514; 1979.

$\rightarrow$ Martin, G. R. Isolation of a pluripotent cell line from early mouse embryos cultured in medium conditioned by teratocarcinoma stem cells. Proc. Natl. Acad. Sci. 78:7634-7638; 1981.

Matsui, Y.; Zsebo, K.; Hogan, B. L. M. Derivation of pluripotential embryonic stem cells from murine primordial germ cell in culture. Cell 70:841-847; 1992.

Mersmann, H. J. The pig as a model for aberrations associated with carbohydrate and lipid metabolism. In: Tumbleson, M. E., ed. Swine in biomedical research. Vol. 2. New York: Plenum Press; 1986:981995.

Michalopoulos, G.; Russel, F.; Biles, C. Primary culture of hepatocytes on human fibroblasts. In Vitro Cell. Dev. Biol. 15:796-806; 1979.

Montesano, R.; Matsumoto, K.; Nakamura, T., et al. Identification of a fibroblast-derived epithelial morphogen as hepatocyte growth factor. Cell 67:901-908; 1991a.

Montesano, R.; Schaller, G.; Orci, L. Induction of epithelial tubular morphogenesis in vitro by fibroblast-derived soluble factors. Cel 66:697-711; 1991b.

Mori, M.; Yamaguchi, K.; Abe, K. Purification of a lipoprotein lipase-inhibiting protein produced by a melanoma cell line associated with cancer cachexia. Biochem. Biophys. Res. Commun. 160:10851092; 1989.

Nakamura, T.; Nawa, K.; Ichihara, H. Partial purification and characterization of hepatocyte growth factor from serum of hepatectomized rats. Biochem. Biophys. Res. Commun. 122:1450-1459; 1984.

Pease, S.; Braghetta, P.; Gearing, D., et al. Isolation of embryonic stem (ES) cells in media supplemented with recombinant leukemia inhibitory factor (LIF). Dev. Biol. 141:344-352; 1990.

Perraud, F.; Dalemans, W.; Gendrault, J. L., et al. Characterization of trans-immortalized hepatic cell lines established from transgenic mice. Exp. Cell Res. 195:59-65; 1991.

Prat, M.; Narsimhan, R. P.; Crepaldi, T., et al. The receptor encoded by the human c-MET oncogene is expressed in hepatocytes, epithelial cells, and solid tumors. Int. J. Cancer 49:323-328; 1991.

Rheinwald, J. G.; Green, H. Formation of a keratinizing epithelium in culture by a cloned cell line derived from a teratoma. Cell 6:317-330; 1975.

Rheinwald, J. G.; Green, H. Epidermal growth factor and the multiplication of cultured human epidermal keratinocytes. Nature 265:421-424, 1977.

Richardson, U. I.; Tashjian, A. H.; Levine, L. Establishment of a clonal strain of hepatoma cells which secrete albumin. J. Cell Biol 40:236-247; 1969.

Robertson, E. Embryo-derived stem cell lines. In: Robertson, E., ed. Teratocarcinomas and embryonic stem cells: a practical approach. Oxford: IRL Press; 1987:71-112. $\rightarrow$ Rohme, D. Evidence for a relationship between longevity of mammalian species and life spans of normal fibroblasts in vitro and erythrocytes in vivo. Proc. Natl. Acad. Sci. USA 78:5009-5013; 1981.

Sand, T. E.; Christoffersen, T. A simple medium for the study of hepatocyte growth in culture under defined conditions. In Vitro Cell. Dev. Biol. 24:981-984; 1988.

Sawada, N.; Tomomura, A.; Sattler, C. A., et al. Effect of extracellular matrix components on the growth and differentiation of cultured rat hepatocytes. In Vitro Cell. Dev. Biol. 23:267-273; 1987.

Schmitt, R. M.; Bruyns, E.; Snodgrass, H. R. Hematopoietic development of embryonic stem cells in vitro: cytokine and receptor gene expression. Genes Dev. 5:728-740; 1991.

Sells, M. A.; Chernoff, J.; Cerda, A., et al. Long-term culture of human fetal liver cells that synthesize albumin. In Vitro Cell. Dev. Biol. $21: 216-$ $220 ; 1985$.

Sigal, S. H.; Brill, S.; Fiorino, A. S., et al. The liver as a stem cell and lineage system. Am. J. Physiol. 263:G139-G148; 1992.

$\rightarrow$ Sirica, A. E.; Richards, W.; Tsukada, Y., et al. Fetal phenotypic expression by adult rat hepatocytes on collagen gel/nylon meshes. Proc. Natl. Acad. Sci. 76:283-287; 1979.

Smith, T. A.; Hooper, M. L. Medium conditioned by feeder cells inhibits the differentiation of embryonal carcinoma cultures. Exp. Cell Res. 145:458-462; 1983.

Southern, P. J.; Berg, P. Transformation of mammalian cells to antibiotic resistance with a bacterial gene under control of the SV40 early region promoter. J. Mol. Appl. Gen. 1:327-341; 1982.

Stone, R. T. Isolation and characterization of recombinant cDNA clones corresponding to developmentally regulated genes in pig liver. J. Anim. Sci. 67:1082-1089; 1989.

Strain, A. J.; Ismail, T.; Tsubouchi, H., et al. Native and recombinant human hepatocyte growth factor are highly potent promoters of DNA synthesis in both human and rat hepatocytes. J. Clin. Invest. 87:1853-1857; 1991.

Talbot, N. C.; Rexroad, C. E.; Pursel, V. G., et al. Culturing the epiblast cells of the pig blastocyst. In Vitro Cell. Dev. Biol. 29A:543-554; 1993.

Talbot, N. C.; Rexroad, C. E.; Powell, A. M., et al. A continuous culture of pluripotent fetal hepatocytes derived from the 8-day epiblast of the pig. Submitted to In Vitro Cell. Dev. Biol., 1994.

Tong, J. Z.; Lagausie, P.; Furlan, V., et al. Long term culture of adult rat hepatocyte spheroids. Exp. Cell Res. 200:326-332; 1992.

Williams, G. M.; Burmudez, E.; Scarmuzzino, D. Rat hepatocyte primary culture. III. Improved dissociation and attachment techniques and the enhancement of survival by culture medium. In Vitro Cell. Dev. Biol. 13:809-817; 1977.

Wilson, J. W.; Groat, C. S.; Leduc, E. H. Histogenesis of the liver. Ann. NY Acad. Sci. 111:8-24; 1963.

$\rightarrow$ Zarnegar, R.; Michalopoulos, G. Purification and biological characterization of human hepatopoietin A, a polypeptide growth factor for hepatocytes. Proc. Natl. Acad. Sci. USA 87:1252-1256; 1989. 